\title{
Establishing the Framework for Using Photos in Art Therapy (and other Therapies) Practices
}

\author{
Judy WEISER ${ }^{1}$ \\ jweiser@phototherapy-centre.com
}

Recibido: 07/11/14

Aceptado: 11/11/14

\begin{abstract}
What is PhotoTherapy and how does it differ from Therapeutic Photography? Is PhotoTherapy simply "Art Therapy using photos", or something different? And what, then is "Photo-Art-Therapy"? Is all this confusing? Yes! And in this Article written specifically for an Art Therapy Journal readership, I hope to provide a useful framework for positioning each of these in terms of their relationship to the others, and clarify their similarities and differences, including the areas where they overlap -- and explain the criteria used for distinguishing between them.

I will explain the "Continuum of Photo-based Therapy Practices" (with PhotoTherapy at one end, and "Therapeutic Photography" at the other) that is in common use around the world for positioning one's practice so that others will be able to easily understand what it is. I will then locate the subcategory of "Photo-Art-Therapy" from within this context. I will then illustrate with "real-life" examples how I (both a U.S. Registered Art Therapist and Canadian Registered Psychologist) have used my knowledge of Art Therapy theory and practice to enhance the potential effectiveness of my PhotoTherapy work during therapy sessions with clients -- in ways that therapists and other mental health professionals who have not been educated about Art Therapy would be unable to do (or understand).

By the end of this Article, I hope that readers will recognize that, whether an Art Therapist works from the "art-during-therapy" ("Art Psychotherapy") model of practice or the "art-as-the-therapyitself" (Therapeutic Art Activities") model, they can benefit from adding PhotoTherapy techniques to their repertoire of adjunctive interventions: using their clients' own personal snapshots and family photographs (and their interactions with these) to evoke feelings, thoughts, and memories -and related values, beliefs, attitudes, and expectations) in ways not possible when using other art media (or words) alone.

After the definitions have been clarified and examples illustrated, the final Section of this Article will provide readers with information about many current practitioners in Spain (and how to contact
\end{abstract}

\footnotetext{
${ }^{1}$ Judy Weiser, Registered Psychologist, Registered Art Therapist, Consultant and International Trainer and Author of the classic text "PhotoTherapy Techniques: Exploring the Secrets of Personal Snapshots and Family Albums" -- is the Founder and Director of the PhotoTherapy Centre in Vancouver, Canada (607-1027 Davie St., Vancouver, Canada V6E 4L2; 604-689-9709; jweiser@phototherapy-centre.com - her website can be seen at: http://www.phototherapycentre.com
} 
them), who have long been using photos during their therapy work or as therapeutic/healing activities for self or others. Some are Art Therapists and some are not --and their differences will clearly illustrate the flexibility of the beneficial "partnership" of PhotoTherapy and Art Therapy.

Key words: phototherapy, art therapy, photo, therapeutic, Weiser

\section{Referencia normalizada}

WEISER J. (2014). "Establishing the Framework for Using Photos in Art Therapy (and other Therapies) Practices". En Arteterapia: Papeles de arteterapia y educación artística para la inclusión social Vol.: 9. Páginas 159-190. Madrid.

\section{CONTENTS}

Clarifying definitions. Definitions used in this Article. Reasons why using photos in therapy is so helpful. The five basic PhotoTherapy Techniques. Therapeutic Photography Techniques. "PhotoArt-Therapy" (and "Therapeutic Photographic Art-Making") Techniques. Examples of PhotoTherapy (with no art-expression involved). Examples of Photo-Art-Therapy (where the "Art-Part" added extra significance to the process). Practitioners in Spain. Conclusion. References..

\section{Clarifying definitions}

In order to discuss "PhotoTherapy", "Therapeutic Photography" "Photo-ArtTherapy" -- and even "Art Therapy", I must first establish a consistent set of definitions for readers, because many people in different countries use these words very differently without realizing they are not sharing the same meaning for those words. This can also happen even within one country, as the various Art Therapy Training Programs in that country can often differ on what the definition of Art Therapy should be for their students -- and thus the Art Therapists they graduate will often make inaccurate assumptions about the kind of work being done by a colleague. Thus the answers to the questions asked at the beginning of this Article will depend directly, of course, upon who is answering (and the way they were educated about what Art Therapy) "should" be!

I want to also remind readers that I am sharing the information below through my own North American experiences and "filters", while also adding information learned through my several decades of teaching outside of North America ${ }^{2}$.

In Canada and the United States, "Art Therapy" is used to describe both "artduring-therapy" and "art-making-as-therapy" [more about this below], while various Graduate Academic or Training Programs seem to just use whichever definition best matches the kind of Programme they offer.

\footnotetext{
${ }^{2}$ I have taught workshops and conducted training about PhotoTherapy in Canada, England, Finland, Germany, Italy, Latvia, Mexico, Netherlands, Scotland, Spain, Sweden, Russia, and U.S.A. -- each of whom seem have their own unique definition of what Art Therapy "truly" is...
} 
The American Art Therapy Association is itself a bit vague about this -- and now that they are considering aligning instead with the Counseling Profession (for better insurance reimbursement and other advantages), their current and future members can only wonder at the different ways the profession is being explained by their national leaders. It would be very useful if they would clarify in writing whether Art Therapy is one or the other of the definitions above -- or perhaps both.

While some professional Art Therapy Associations (such as in England) are more clear about the differences between "Art Psychotherapists" and Artists' "Therapeutic Activity practices ${ }^{3}$, very few others have done so (especially in Italy where I have observed a wide range of different educational paths to becoming an Art Therapist). I have also noticed that in Spain there seems to similarly be a variety of different approaches regarding what an Art Therapist is and does, and therefore how their preparatory education should be structured.

More questions then arise: Is Art Therapy a field onto itself, or only a set of art-based intervention techniques that any properly-trained mental health professional can use, even if they do not have a degree in Art Therapy? Is Art Therapy a Counseling Profession? Or is it simply a collection of art-based techniques that any kind of properly-trained mental health professional, therapist, or counselor can learn to use, even if they know nothing about its underlying theory?? If it is a field onto itself, then does it have its own theoretical foundation? Or does its underlying theory come from a combination of studies of art, psychology, visual perception, and similar?

Are Art Therapy or PhotoTherapy (however one capitalizes it ${ }^{4}$ ) both professional fields whose practices can be done only by those with University education and later supervised training as Mental Health Professionals -- or is each simply a collection of creative/expressive art-(or photo-) based activities that any person can use to help themselves or others feel better, simply because "making art to make sense" allows the unconscious to communicate directly in imagery and produce healing as a result?

\footnotetext{
${ }^{3}$ The distinction used in the U.K., and only "Art Psychotherapists" can be licensed.

${ }^{4}$ The spelling of PhotoTherapy with the "T" also capitalized in the middle of the world is the original North American spelling from the very first article ever published with that word in its title (Weiser, 1975) and was spelled that way to show the equal power of the "photo" and the "therapy".

This is still the preferred spelling world-wide for the use of photos during therapy, by trained professionals -- although many people have chosen to spell it their own way: "phototherapy" or "Phototherapy", or even "photo-therapy".

And to make things more complicated, others doing Therapeutic Photography, but not realizing that is what they are doing -- particularly pioneers of that field in England named their Therapeutic practices "phototherapy", with a lot of resulting confusion that still continues today
} 
And while the making of art can certainly be "therapeutic" (healing) for those doing it, can this be accurately called "therapy" if there is no end-part of the session where it is de-briefed so that a cognitive-conscious anchoring can be achieved? If the client simply makes art and then goes home, can this be therapy? These questions not only will likely never be answered, but also are beyond the limited discussion space provided here -- however I believe that they do deserve serious contemplation and discussion by all Art Therapy Educators.

This article will simply point out that these inconsistent definitions are serious issues that are not only often confusing for people trying to understand what "Art Therapy" means, but also portend even less success in finding a globallyconsistent definitive answer to be possible in the future. All this then bears direct importance for any Art Therapist wanting to include PhotoTherapy or Therapeutic Photography techniques in their helping repertoires -- which I believe they should be doing, considering the increasing importance of "everyday photography" in the lives of the clients they want to help.

PhotoTherapy has had a much better history of clarifying such differences, primarily because each of the three early pioneers was either a Psychologist (myself and Dr. David Krauss) or Psychiatrist (Dr. Joel Walker), all of whom discovered the existence of Art Therapy only after more than a decade of therapeutic practice, publications, conferences, presentations and workshops had already occurred. When we realized the benefits of additional training in Art Therapy techniques to our PhotoTherapy practices, we implemented the parts we felt competent to use -- and did the same when later encountering a long list of other "new" (to us) techniques such as Family Systems Theory and Therapy, NeuroLinguistic Programming techniques, and more recently, the exciting new information from Neuroscience.

The operational definitions for PhotoTherapy and the closely-related technique of "Therapeutic Photography" can be found below, along with those of "Art Therapy" and "Therapeutic Art-Making" -- as are the definitions for the later terms "Photo-Art-Therapy and "Therapeutic Photo-Art-Activities", which were later formally added to the PhotoTherapy lexicon to explain the "place" where all these practices intersect.

\section{Definitions used in this article}

PhotoTherapy techniques are therapy practices that use people's personal snapshots, family albums, and pictures taken by others (and the feelings, thoughts, memories, and associations these photos evoke) as catalysts to deepen insight and enhance communication during their therapy or counseling sessions (conducted by trained mental health professionals), in ways not possible using words alone.

It is extremely important to correct the erroneous belief that PhotoTherapy techniques are just simply "Art Therapy using photos" as one more art medium during expressive arts or even collage activities. In fact, they are not "Art Therapy" at all -- as will be explained further below. 
PhotoTherapy techniques are instead photo-based interventions that any kind of trained mental health professional can use to improve their practice, including Psychologists, Psychiatrists, Family Therapists, Narrative, Play, or Drama Therapists -- and also (but certainly not limited to), Art Therapists.

PhotoTherapy is an interactive system of techniques that make use of people's personal snapshots and family albums as "openers" to access feelings, thoughts, and memories that are often not easily available to solely-verbal methods of inquiry during their therapy sessions. It is not a field onto itself, but rather just simply an interactive collection of intervention techniques that can be used when the therapist thinks they will be particularly helpful in activating process toward the therapeutic goal of that session.

Any kind of therapist who wants to add PhotoTherapy techniques to their collection of intervention skills can be educated/trained to do so. However, they can be particularly beneficial adjuncts for Art Therapists who are, of course, particularly knowledgeable about many deeper layers of potential symbols and archetypal content of images than those with no Art Therapy Training. More about the similarities and differences between PhotoTherapy techniques and those of Art Therapy (the "art-during-therapy" / "art psychotherapy" model), can be found in Weiser, 1993/19995.

However, I want to add here one particularly valuable comparison by Krauss included in those above-referenced pages:

"Although both Art Therapy and PhotoTherapy utilize the methodology of pictorial projection, it would seem initially that they do so in very different ways. Art Therapy relies on a client's internal concerns to emerge from the unconscious through the process of a drawing spontaneously produced by the client -- and external stimuli, light, or content need not be available at the time the client draws a picture for an image to appear in the drawing...

"Photographs, on the other hand, will be taken at the place where the physical content actually exists [or its symbolized form appears or is arranged to appear]. A photograph of a house will use as content some physical representation of a house.

"Since Art Therapy is dependent upon externalized internal subjects, and PhotoTherapy is dependent on internalized external subjects, it appears as though they deal with different aspects of personal symbolism."

In contrast to PhotoTherapy, Therapeutic Photography techniques are photographic practices done by people themselves in situations where the skills of a trained therapist or counselor are not needed -- for example, where photo-taking, viewing, sharing, or discussing can help increase people's own self-insight and

\footnotetext{
${ }^{5}$ For more about the similarities and differences between PhotoTherapy techniques and those of Art Therapy (the "art-during-therapy" model that is), see Weiser,1993/1999, pages 9-12.
} 
awareness, improve their relationships with family and others, and lead to desired changes in their lives.

An extension of Therapeutic Photography is "Social Action Photography" Projects which are intentionally-planned photo projects created for the goal of increasing well-being, activate positive social change, and reducing social exclusion in participants of such Project groups -- as well as (when possible) also in those viewing later presentations about the Project's results. Additional benefits of Social Action Photography Projects frequently include lessening prejudice and conflict through increasing understanding and strengthening bonds in communities (and society in general), assisting in rehabilitation, deepening intercultural communications, bringing attention to issues of social injustice, sharpening visual literacy skills, enhancing education, expanding qualitative research and prevention methodologies, and producing other kinds of photo-based personal/emotional healing and learning. It is of course acceptable for a therapist to be involved in organising or leading such projects, but this is certainly not a requirement.

Photo-Art-Therapy techniques are a specialized adaptation of PhotoTherapy Techniques -- and therefore similarly are therapy practices -- that are used only by professional Art Therapists with education, training, and recognized qualifications in Art Therapy itself (using the "art-during-therapy" or "art psychotherapy" model). These Art Therapists will always be better at recognizing deeper levels of the images, which those with no such Art Therapy knowledge will likely not see, simply because they do not know to look for such things.

In "parallel" with the "sub-category" positioning model explained above, the use of photo-art interactive activities by Art Therapists who prefer the "art-astherapy" model is called "Therapeutic Photo-Art-Making Activities" (and it can be similarly viewed as a sub-category of "Therapeutic Photography" techniques). And to close the "parallel" alignment completely, "Social Action Photography Projects" can be seen to be a similar positioning as use of "Social Art Practices" in Art (as) Therapy applications ${ }^{6}$.

It is important to note that none of the above techniques are limited to using only "paper-printed photographs": these techniques can all be used with any kind of photographic imagery, both paper and digital, both still and moving -- therefore also including applications in digital or mobile phone photography, online photo albums, DVDs and films -- and also in VideoTherapy, Video Art Therapy, and/or Therapeutic Videography ("Therapeutic Film-making") applications ${ }^{7}$-- as the primary work is about the image and not the technology that produces it...

\footnotetext{
6 "Social Art Practices" website at: www.scoop.it/t/social-art-practices and the related "Social Practices Art Network" at: www.socialpracticesart.network.org

${ }^{7}$ My invited next Article for this Journal will explain, describe, and illustrate Video-based therapy and therapeutic activities through a similar comparison framework and continuum model
} 


\section{Reasons why using photos in therapy is so helpful}

A photograph is simultaneously a realistic illusion and an illusory reality, a moment captured from within time, yet never able to be fully captured in its pure form when stilled as an artifact of time. We use the film to stop time, which cannot be stopped. These aspects are crucial for an understanding of why (and how) PhotoTherapy works: it permits the complex examination of a frozen slice of time fixed forever onto film as 'fact', and yet at the same time brings forth an appreciation of the endless variety of realities that it visually-symbolic presents differently to each viewer, each time it is seen.

Viewing a photograph immediately connects people with the moment it was taken. They are "there" inside it, participating in that experience as if their eyes were the lens of the camera itself. Their mind does not realize they are looking at a piece of paper or computer screen. Instead they are immediately put into the picture as if that moment in the photograph was happening right now: they are there viewing it in three dimensions and with all the accompanying sounds, smells and other sensory information as when that moment originally happened, even if it was taken many decades ago. A photo has the ability to transport people in time and to let them consider alternative realities, even if neither of these is possible in real life.

What does the unconscious hide underneath the surface of a personal snapshot or a family album? There is absolutely no way to know this answer -- because it is not possible to fully know what is hidden inside the unconscious of any person (which is the reason that it is named the "UNconscious"). Neither can the photo be read "like a book" from an outside-observer position, because it shares its story differently, and selectively, to each person who sees it.

What is known, however, is that the power of that photograph -- and the reasons it was taken or kept -- all usually "live" in the unconscious, and that if the right kinds of questions are asked by those trained in how to use them, it will be possible to discover a lot more about the person telling you about that photo, while they think they are talking about what can "obviously" be viewed on its surface!

Because personal snapshots and family photos are visual metaphors for an actual moment of "living experience" (and thus capturing any "raw" feelings that were happening all-at-once there when time was stopped), they can greatly assist clients in remembering, confronting, imagining, and exploring complex parts of themselves, their lives, and especially their feelings.

Using their own photographs (or even just their reactions to other people's images) as a bridge into their own "personal unconscious" also gives clients added support in the process of dealing with the related thoughts, feelings, and associated memories that often arise with unexpected intensity when snapshots are used as a focusing lens.

Ordinary personal snapshots serve as 'mirrors with memory', visual footprints marking where people's lives have taken them or perhaps pointing the way to where they might next be going. Worked with as representational objects, sym- 
bolic self-constructs, or transitional objects, a much deeper form of "in-sight" can emerge when photos are used to help people bridge into the emotional life of the unconscious in ways that words alone cannot fully match.

PhotoTherapy techniques are successful because every photograph a person chooses to take, keep, or respond to is in some ways a self-portrait. In permanently recording these important moments and the embedded feelings captured within them, personal photos become "bridges" for accessing, exploring, and communicating about feelings and memories, as well as related psychotherapeutic issues these evoke.

As clients begin to interact with their own personal and family photos under a therapist's guidance, they talk about the emotional meaning "inside" their photos, in addition to the "visual details" on their surface. During this process, many associated thoughts and feelings will spontaneously emerge and thus be more available for conscious and cognitive exploration and integration.

When people look at photos they themselves created -- and review the themes, messages, and emotional content unknowingly embedded in these -- they are able to learn more about their own unconscious inner life. In communicating more directly with the unconscious, visual symbols permit the natural bypassing of verbal "filters" (and accompanying rationalizations, excuses, and similar protective defenses) that automatically limit clients' direct connection with powerful feelings, thoughts, and memories.

During PhotoTherapy sessions, photos are not just passively reflected upon in silent contemplation, but also actively created, posed for, talked with, listened to, reconstructed, revised to form or illustrate new narratives, collected on assignment, re-visualized in memory or imagination, integrated into art therapy expressions, or even set into animated dialogue with other photos. The therapist will instruct the client according to the therapeutic goal for that session: having the client work with photos one-by-one, in various arrangements or collages, in direct dialogue with the client, or additionally "decorated" using art materials to help expand their stories and purposes -- always with the session's therapeutic goals in mind.

None of this requires that the therapist have any knowledge about Art Therapy, although if they do, then the value of such additional artistic expression can of course lead to discoveries not available to a therapist who has not received such training.

Making the photos, or bringing them along to the therapy session, is just the start -- once the photo can be viewed, the next step is to activate all that it brings to mind (exploring its visual messages, entering into dialogues with it, asking it questions, considering the results of imagined changes or different viewpoints, and so forth). What for photographers is usually an end-point (the finished photo) is, for PhotoTherapy purposes, just the beginning...

The therapist's primary role is to encourage and support clients' own personal discoveries while exploring and interacting with the ordinary personal and family snapshots they view, make, collect (such as postcards, magazine photos, greeting 
cards, and so forth), remember, actively reconstruct, or even only imagine. Therefore, the interactive model of the five basic PhotoTherapy techniques presented below is directly connected with the five primary kinds of photographs -- which are frequently used in various combinations with one another, although they must be individually separated in order to describe and explain them:

\section{The five basic phototherapy techniques}

The techniques of PhotoTherapy and Therapeutic Photography have previously been explained and illustrated in great detail elsewhere ${ }^{8}$, so the following will simply provide only a brief summary:

Very simply, the five basic techniques of PhotoTherapy are directly related to the various relationships possible between person and camera (or, person and photograph) -- although in practice these categories often naturally overlap. These techniques are briefly summarized below'

1) Photos which have been taken or created by the client, whether actually using a camera to make the picture, or "taking" (appropriating) other people's images through collecting "found" photos from magazines, postcards, Internet imagery, digital manipulation, and so forth;

2) Photos which have been taken of the client by other people, whether posed on purpose or taken spontaneously while the person was unaware of being photographed -- but where people other than the client have made all the decisions about timing, content, location, and so forth;

3) Self-portraits, which means any kind of photos that clients have made of themselves, either literally or metaphorically -- but where in all cases they themselves had total control and power over all aspects of the image's creation;

4) Family album and other photo-biographical collections, whether of birth family or family of choice; whether formally kept in albums or more "loosely" combined into narratives by placement on walls or refrigerator doors, inside wallets or desktop frames, into computer screens or family websites, and so forth -- which were put together for the purpose of documenting the personal narrative of the client's life and the background from which they developed. Such albums have a "life" apart from, and far beyond, the individual images which comprise them;

5) The final technique, "Photo-Projectives" is based on the fact that the meaning of any photo is primarily created by its viewer during their process of viewing it (or taking or even just planning it), and thus any photograph that draws interest from client or therapist has potential use in the counselling setting.

\footnotetext{
${ }^{8}$ Both in my book (Weiser, 1993/1999) and in many other Chapters and Articles publications, which can be found listed at: www.phototherapy-centre.com/biography.htm

${ }^{9}$ More detailed information about each individual technique (along with case-anecdotal illustrations) can be found in my previous publications, as well as in individual pages linked from the list on the webpage at: www.phototherapy-centre.com/five_techniques.htm
} 
This final technique actually underlies all interactions between people and snapshots, and deals with the ways and reasons that a person gets any meaning from any photograph in the first place. It is called "Photo-Projectives", in that meaning is always projected onto a photographic object when any viewer encounters it, rather than it somehow universally triggering the same objective meaning for all viewers.

Therefore, this technique is located not in a particular kind of photograph, but rather in the less-tangible interface between a photo and its viewer (or maker), that "place" inside each person where they form their own unique responses to what they see. For this reason, although this final technique is more an integral part of the other four than it is independent onto itself, it must still be discussed separately (and preferably taught first when training therapists to use it).

Each kind of photo-person interaction (technique) has its unique benefits and limitations, and each can be worked with not only on its own, but also in combination with the other four kinds/techniques, as well as combined with various expressive arts media or otherwise-appropriated imagery, in order to additionally enhance the therapeutic process. Once trained in the interactive system of these adjunctive tools, therapists from any mental health profession can develop their own approach for applying these techniques most appropriately for their own particular kind of client-population or setting.

It is important to emphasize that the choice of which technique(s) to use at what time is the Therapist's choice and not the client's -- and that, in any particular therapy session, the therapist may actually decide to use no photos at all that day. These techniques are to be used when helpful for the therapeutic process that is happening that day -- or not used if the therapist thinks it is important to do something different (including just talking, if that seems the best approach at that time).

It is also important to note that, because the techniques of Photo Therapy are about photos as personal/emotional communications rather than as "art", the "art part" of photos (composition, focus, tonality, etc.) is simply not relevant to such practices. Therefore, the practitioner does not need to be a photographer -- or even know anything about photography or photographic art -- in order to use these techniques.

Since it is instead the "heart part" (the emotional contents) of photos that is essential, there is therefore no need to have any prior experience with cameras or the photographic arts, to use these techniques effectively. In fact, therapists who have had past training in the "art" of photography sometimes find their own assumptions (regarding photographic evaluation, deconstruction, or outsiderinterpretation criteria) seriously challenged while training to use PhotoTherapy or Therapeutic Photography techniques, because their previous experience with art photography often intrudes.

Since PhotoTherapy techniques are a collection of adjunctive "activating" tools, rather than fixed directives based upon only one specific theoretical modal- 
ity or therapeutic paradigm, they can be used by any kind of trained therapist, regardless of that person's conceptual orientation, professional affiliation, preferred intervention model or approach. This is one of the many ways that PhotoTherapy is both similar to, yet distinct from, Art Therapy -- as well as the reason it can be used so successfully by a variety of other mental health professionals who are not be trained in Art Therapy specifically.

Therefore, since PhotoTherapy is about photography-as-communication rather than photography-as-art, no prior experience with cameras or the photographic arts is required for effective therapeutic use.

And since these techniques involve people's interactions with their own uniquely personal visual constructions of reality, they can be particularly successful with people for whom verbal communication or interaction is physically restricted and/or socio-culturally limited, difficult, or situationally inappropriate - thus helpful in special education, multicultural, and other complex settings where people have been socially excluded or marginalized, often for misunderstanding nonverbal cues.

Therefore PhotoTherapy can be especially helpful, and usually very empowering, in applications with situations of social exclusion -- as well as beneficial in diversity training, conflict resolution, divorce mediation, and other related fields.

\section{Therapeutic photography techniques}

As explained above, PhotoTherapy is the use of ordinary snapshots, and interactions with them, within an intentional framework of therapeutic practice, where trained mental health professionals use these techniques as an integral part of their ongoing therapy process when counselling their clients -- whether or not the photos are used in any particular session or not.

In contrast, Therapeutic Photography is the use of photographs in selfinitiated (rather than therapist-instructed) photo-based activities, done by individuals themselves (or with others) for the purpose of their own personal growth and self-discovery (finding that simply doing photography can be very" healing and soul-nourishing"10.

Therapeutic Photography is done for people's own personal insight, selfexploration, or "artistic statement" purposes, as an agent of personal, political, or social change), as well as for many other reasons. But in all these instances, these kinds of photo-based therapeutic/healing activities are always done outside any formal counselling context (i.e., no therapist is formally involved or guiding the experience, or discussing it later with the person, as part of their larger therapy process).

And in significant contrast to the description above about how PhotoTherapy techniques are used by therapists --where the regular therapy sessions happen

\footnotetext{
${ }^{10}$ Rosemary Tyksinski, on: http://preconsciouseye.com
} 
whether or not photos or discussions about them might not be used that day -- in the case of Therapeutic Photography activities, if no photos (or photo-discussing) are happening on a given day, then the session itself does not happen.

The techniques of Therapeutic Photography follow the same list of five listed for PhotoTherapy above -- the major difference being simply that the practices of Therapeutic Photography are not done as part of an intentional therapy framework, and do not require the knowledge and experience that a trained therapist can bring to such encounters.

It is helpful to view PhotoTherapy and Therapeutic Photography as two endpoints of a continuum along which all photo-based healing/helping practices can be positioned: "photography-during-therapy" at one end and "photography-astherapy" at the other -- with a lot of flexibility (and room for overlap and fluid movement) in the middle. However, the two practices are not opposites (nor adversarial) and in fact overlap where they intersect, since PhotoTherapy naturally includes many aspects of Therapeutic Photography, though taking it several steps deeper into guided unconscious process work.

They are simply contrasting ways of using emotional information that has been unconsciously embedded in people's personal snapshots: one requires the involvement of a professionally-trained counselor to formally guide and support the process, whereas the other doesn't. One emphasizes the therapy while the other, the photography.

One easy way to clarify whether it is PhotoTherapy or Therapeutic Photography being done, lies in answering these two questions:

1) Does the session require that a therapist direct it? -- and -- 2) If there were no photographic activities happening during that particular session, would the session still be happening anyway? If the answer to either is "yes", then it's a PhotoTherapy session happening, and if the answer to both is "no", then it's a Therapeutic Photography one instead.

People often decide to use their camera in personally-therapeutic ways; for example, as an agent of personal or social change, whether through private photographic activities or for public exhibition as a personal, artistic, and/or political statement. But doing such things also can bring up deep memories and strong emotions surprisingly quickly, which can sometimes be quite overwhelming for people who are not already experienced in knowing how to cope with such things when they suddenly appear.

Since no prior training in therapeutic theory or counselling skills is required for those doing Therapeutic Photography, there is no protective counselling framework in place with which to immediately contain and resolve any emotional consequences that might erupt for people participating in those activities.

People can easily become confused about the differences between therapy and self-help. Even therapists sometimes mistake "activities" for the therapy itself -- 
and this error is much more significant to those involved in either process than it may initially appear. To paraphrase a colleague, "making someone feel good taking or viewing or talking about photos is not the same as therapy"11 -- and cocreation of art is not the same as "doing therapy", either -- even when the therapist is helping to produce it. Therapy is more than this, at least in most countries.

It is my opinion that, in order for "real" PhotoTherapy to be taking place, clients must not only go through the process of interacting with their snapshots, but consciously probe and subsequently cognitively re-integrate these photoprecipitated experiences, while under the active guidance of a trained therapist, so that these insights can continue to provide a better understanding by remaining available for later conscious recollection and integration.

Therefore, doing Therapeutic Photography by oneself, even within a group setting that includes peer feedback, may actually precipitate the need for a therapist to help "finish" what has come to light during activities that took place without one. In contrast, working with photo-triggered personal insights and emotional reactions within the formal structure of deeper therapy process, is the very definition, function, and purpose of PhotoTherapy itself.

It is obvious that many people currently doing PhotoTherapy or Therapeutic Photography may still not know that these practices are being called by these particular names elsewhere. Others may well be doing the work under those titles, but are simply not as publicly visible through writing, publishing, or establishing websites, and thus never hearing of each other's work (nor the larger networks that exist ${ }^{12}$ for exchanging information).

To complicate this picture further, but in a good way, many professionallytrained therapists who are also interested in photography itself, have developed practices that represent partnerships of the two (combining PhotoTherapy and Therapeutic Photography in their work with clients) ${ }^{13}$ : having their clients engage in Therapeutic Photographic activities directly, as a means of more actively exploring themselves -- and then bringing the resulting images back into their own formal therapy sessions so that deeper counselling work can occur as a result of the combination of approaches. And to add to the complication, though in not such a good way, is the reality that some people who call themselves "phototherapists" are not therapists at all (at least, not in the North American sense) $)^{14} \ldots$

\footnotetext{
${ }^{11}$ Myra Levick, personal email communication, September 2, 2000.

${ }^{12}$ For more information about dozens of current practitioners and programs around the world, using both kinds of photo-based techniques, see the "Who is Doing What, Where" and the "Related Links" pages at: www.phototherapy-centre.com

${ }^{13}$ For example, British practitioner Field: http://www.therapystudio.co.uk/ and American FisherTurk: http://photographytherapy.com/

${ }^{14}$ This is usually in countries where the word "therapy" itself often signifies different meanings than in North America. So lack of familiarity with these definitions by those who do not undertand
} 
As one of the long-time trainers for the field of PhotoTherapy, I believe that even though Therapeutic Photography is not therapy, it is still very important for practitioners of both fields to understand the mutual similarities of these two approaches -- as well as respect the boundaries imposed by their differences (and implications thereof) -- for the benefit of those who will receive either kind of services.

\section{"Photo-art-therapy" (and "therapeutic photographic art-making") techniques}

Art therapy techniques have evolved based on the unique ability of the arts to serve as a symbolic language for expressing that which words cannot tell. These adjunctive tools have greatly improved the verbal therapy process that, for far too long, was a therapist's only choice.

As mentioned above, properly trained Art Therapists can guide a person's interactions with art media to a much deeper level than those without specific additional training or education in Art Therapy or Therapeutic Art -- and those who have added photos to their collection of art media options, can similarly take a person's interactions with photos to a much deeper level, as well ${ }^{15}$. Therefore, photography -- as probably the most publicly familiar and emotionally powerful of all the artistic media -- has evolved during this same time period to be available as a natural adjunctive tool to greatly assist Art Therapists (who often include photos in their own art-mediated practice or educational programs).

For this reason, the new sub-category of "Photo-Art-Therapy" was given formal recognition by myself and the other two PhotoTherapy "pioneers" as a new part of the PhotoTherapy framework announced at the International PhotoTherapy Conference in Turku, Finland in $2008^{16}$-- in the acknowledgement that therapists with additional training in Art Therapy are able to use PhotoTherapy techniques in ways not available for other therapists without such training.

And in similar recognition to the above, the new title of "Therapeutic Photographic Art-Making" was added to the Therapeutic Photography framework -- a rather awkward title, but one that clearly differentiates the non-therapy use of photo-based art-making activities, done by those with additional specialized focus "Therapeutic Art-making Activities").

the significance of such differences, can cause communication (and perception) problems internationally. Many who previously referred to themselves as "Phototherapists" (especially in England) are beginning to change their terminology (without any negative effects on their practice); however, others have not -- and see no reason to.

${ }^{15}$ Since I have experience in both Psychology and Art Therapy, I am aware of numerous treatment situations where this additional "layer" of knowledge (about Art Therapy) has helped me relieve a client's distress more quickly than I could have ever done without having this "double perspective".

${ }^{16}$ This was announced by me (in collaboration with Dr. David Krauss and Dr. Joel Walker) during my "Invited Plenary Presentation" which opened that Conference. 
It is beyond the scope of this Article to explore the comparisons between "Art Therapy" and "Therapeutic Art" (or similarities and differences between PhotoTherapy and Art Therapy itself) in any further depth, as this has already been done thoroughly elsewhere ${ }^{17}$. However it is important to add here that it seems that the earlier-mentioned conceptual framework of the "PhotoTherapy - Therapeutic Photography Continuum" would be an excellent model for also positioning all the various Art Therapy practices in use in various countries, along a similar Continuum with "art-during-therapy" at one end and "art-as-therapy" at the other. At least this would provide a common terminology for beginning dialogues about which kind of Art Therapy is being done ${ }^{18}$.

\section{Examples of phototherapy (with no art-expression involved)}

Self-Portrait Example: Lee had been HIV-positive for over seven years when he carefully arranged himself for this photograph, placing himself in a baby crib he found in his guest cabin at a holiday resort.

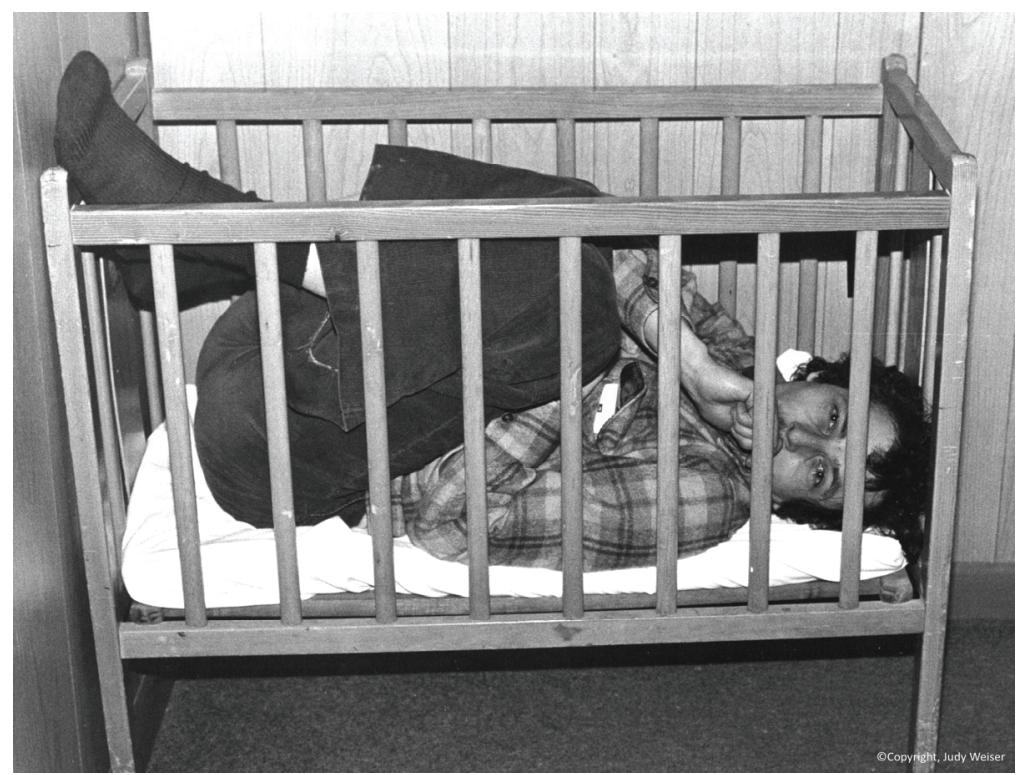

\footnotetext{
${ }^{17}$ This comparison can be viewed in more detail on pages 9-12 of the book "PhotoTherapy Techniques: Exploring the Secrets of Personal Snapshots and Family Albums" -- which includes quoted material authored by Krauss (1983, p. 53)

${ }^{18}$ In addition to the locations mentioned in the previous footnote about this topic, a very thorough presentation of these "Continuum" concepts can be found in my 2004 Article for the Canadian Journal of Art Therapy.
} 
He had a friend take it, but only to act as a "human cable release". For over 15 minutes, he carefully arranged himself into various poses to get the scene as he wanted it -- and then directed her when to hit the shutter on the camera that he had pre-positioned himself, when he felt he had posed exactly as he wanted. Once the film was developed, he had his favorite one printed large, and framed it to keep beside his bed. Apart from that friend, Lee never showed those selfportraits to anyone other than his therapist, who he began seeing for counseling when he realized the time had arrived to begin coming to terms with his approaching death (which has since occurred).

He explained, "When I was a baby, life was good. I was kept clean, warm, and fed. I got unconditional love from my parents. Life was safe and kind. When I first found out that I had been infected by HIV, it was in those very early days of the plague when nobody knew what it was yet, much less how to prevent getting it. So I didn't even know I had been putting myself at risk. When they told me that I would soon get worse from AIDS and then die soon, it put a cold shock right through my body. My heart froze up in fear. I felt like I'd been raped. It was a bunch of really awful feelings. And it just wasn't fair -- because I didn't know [about all this] or I would have protected myself.

"What's this picture about? Well, when I first got diagnosed, I really felt like a little boy crying out, "I want my Mommy"! Seriously, that's the first thing that came to my mind. But she had been dead a long time [by then], so I had nobody to go "home" to, nobody's lap to crawl into. My lover had already died and [the rest of] my family mainly disowned me when they found out I was gay. They don't know I have AIDS, and I won't let them have the pleasure of finding out so they can tell me it is God's punishment. My friends are understanding, but they aren't coping very well with my dying -- and neither am I! I'm not ready yet -not sure if I'll ever be.

"Every time I start thinking about it, I get more scared and really need to find a place that is safe so I can catch my breath, and push AIDS away for a little while. I go relax at a friend's cottage, but that's just for a short time. So when I was at this motel attending a conference, and there was this crib in the room, it really brought back memories of being so little that I fit into one. So when I saw that crib, I just decided on the spur of the moment to climb in. I didn't think about it much -- just climbed in. And you know what? I felt so safe in there...

"So the next day I asked my friend to come up to my room with her camera and I did it again, so that I could remember that there used to be this place once where I was happy and had no worries, when my life was clean and pure -- and where I had no concept of death. Every once in a while I take out this picture again and remember what it must be like to have no fears. It really makes me feel better for a while..." 


\section{Photo-Projective Example:}

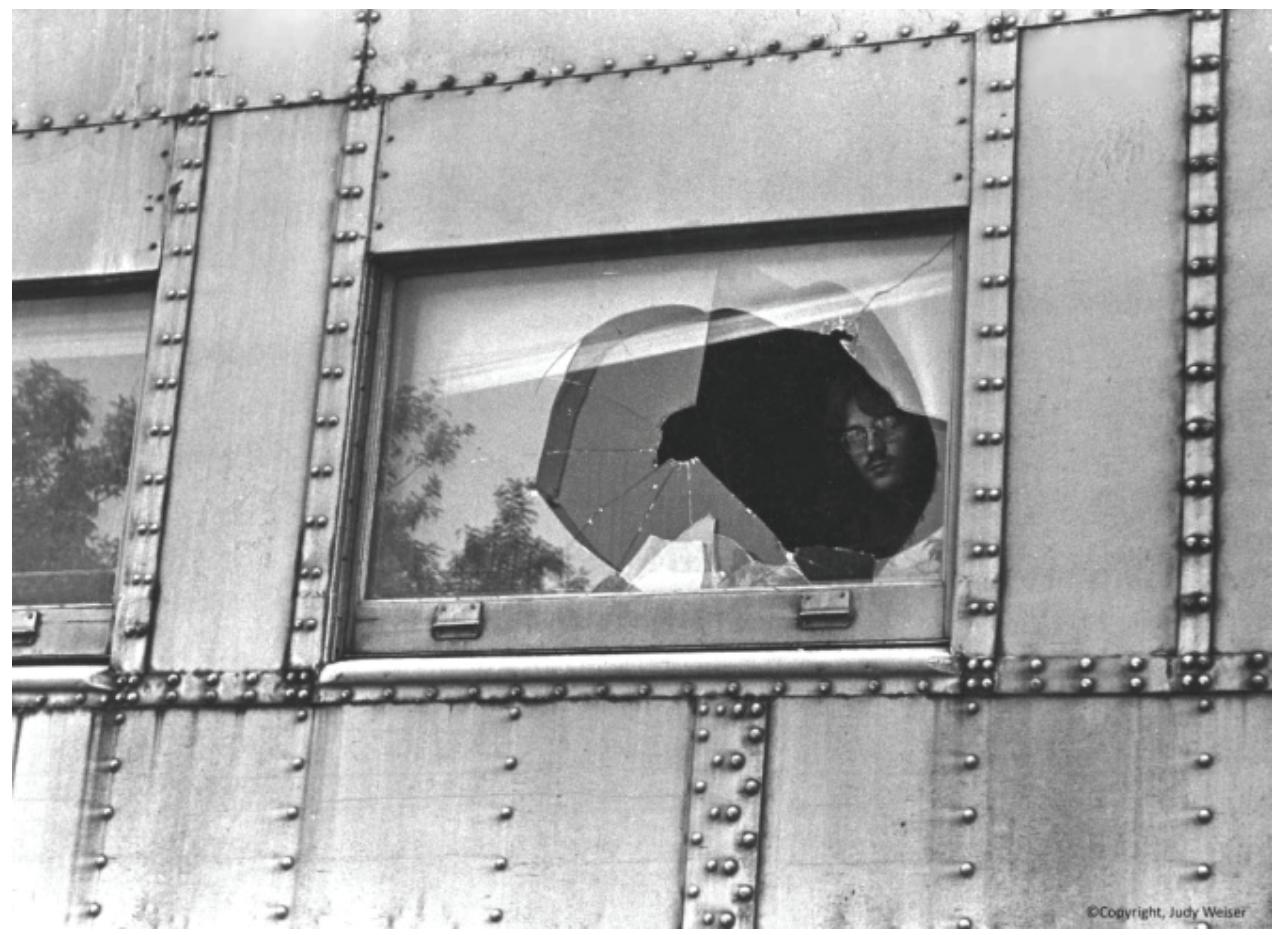

"This particular photograph "called" to me and so I picked it up from the table to look at closer", a woman explained. "It is a photo of someone looking out of a broken window. In the reflection of the window is trees. The walls that the window is attached to are steel with rivets in them. My reflections: Is it a train? A building? A prison? It made me in some ways think of the men I worked with in the prison environment. They were far away from home and even though there were trees around them (it was a Native justice system using traditional healing environments and methods), they were none-the-less in prison.

"Those are aside thoughts. I knew that I chose the photo because it said something about me and not about someone else. I just wasn't sure what it said. I had to sit with it for quite a while to try to understand what it meant. The face in the window looked tired, and that was how I feel. I have been in school for ten years now, and I am just tired. Tired of the constant struggle for money, time, and sanity. Tired of having to constantly fight for what I believe in. And... well... just tired. I have not had any sort of vacation in seven years.

"Why the broken window? And where is the person? I felt the person was on a train that was like a prison. They are going somewhere but they can't get off 
the train until it stops (like my school experience). The only connection they have to the outside world is through the broken window (my occasional glimpses at life ... walking in the park, going for coffee with friends, visiting people).

"The person is not miserable. Just tired. They know that they have to stay on the train and they won't get off until they get to the end of the ride, which may be years and years away. That's how I feel. I had no plans of staying in school this long. I'm not an academic at heart. I wanted to get an art degree, get more skills and maybe write children's books. Here I am ten years later sitting on the same train.

"I have almost forgotten what it is like to live in a world that is not full of so many isolating feelings and tasks like writing (the academic kind, not the creative kind), marks (grades totally perplex and freeze me), the coldness of certain professors (if people keep you at a distance they can keep the hierarchy in place), and the lack of extended periods of being in a relaxing and natural setting to just let my thoughts go.

"As I look back on the image, I could say that I feel somewhat suffocated and constrained. I can see the trees, but I can't touch them. I can see outside of this train-prison, but I can't get off until the ride is over. I could get off if I wanted to, but then I wouldn't be where I need to be. I need to get off in the right place, so I have to suffer this isolating ride. I found this quite enlightening and sad at the same time. Because after all, the train ride goes on for some time still."

Four years after writing the above, she reviewed her words and after looking at the same photo again, she added, "Re-reading my thoughts again now, about the photo of what I envisioned as a train ride, I realize how unhappy I was doing graduate work at that particular time in that particular institution. Yet somehow there was something making me feel that I "should" stay. The "should", not being a "want", made the experience seem like a prison sentence.

"Some time after the [original] phototherapy realization, it took a lot of courage but, I withdrew from the program I was in and continued doing my clinical work. I immediately felt a burden lifting and felt that I was outside in the trees once again. I am now in a postgraduate clinical training program, but it is a "want" and not a "should" and I no longer feel as if I am on the train. I feel as if I now periodically ride on the train, but I am now enjoying the scenery and know that I can step off and take in view when I feel the need." 


\section{Family Photo Example:}

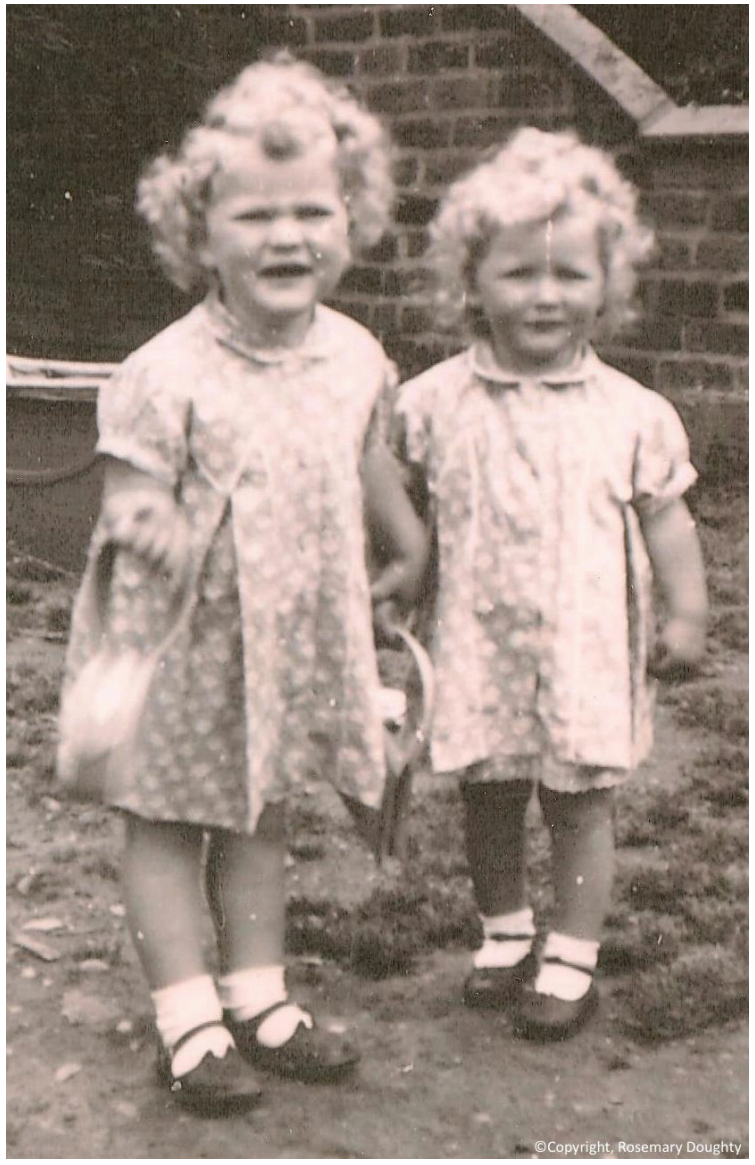

"This is my photo of my late sister, who died in 1992 at the age of 43 . She is holding my hand. It helps me find answers to the question of my persisting identity. It is in my nature, or soul, to see the world through eyes of innocence, openness and amazement, despite a great variance in what I bear witness to and experience. I have never lost my childhood sense of wonderment, even though I am retired now. It is spiritual for me, this picture -- and through it, my spirit connects me in life with her and also my other sister, both of whom died young, and my spirit keeps me alive to the thriving, existing world around me. It was good for me to learn this again". 
Examples of photo-art-therapy (where the "art-part" added extra significance to the process):

First Self-Portrait where Art Therapy knowledge provided additional insights:

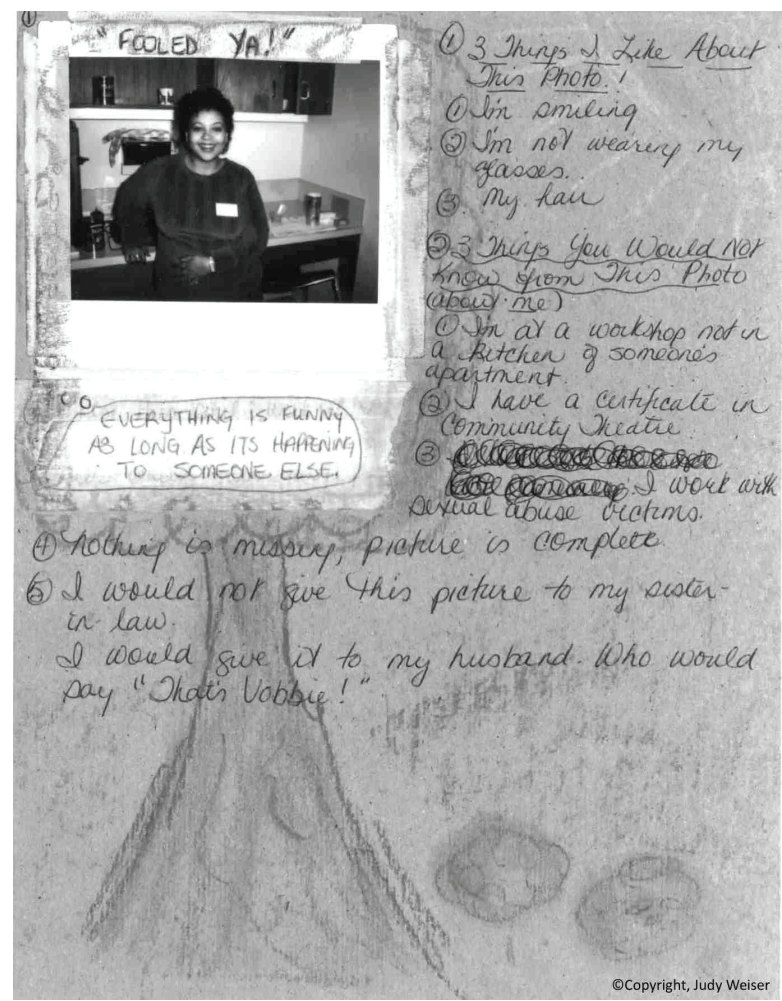

The photo above was created in response to a self-portrait assignment during a Introductory PhotoTherapy Workshop I taught one weekend for therapists of all kinds. On the first day, participants were instructed to go outside with Polaroid cameras (provided) and return with an informal photo of themselves -- to take only one photo and bring it back whether or not they liked it (no other "rules" except that their face had to be part of it). Then they had to secure it to a piece of cardboard and "decorate" it however they wished with art materials provided, while at the same time answering ("using words and/or art expressions, whatever they preferred") a list of questions provided on a separate piece of paper. 
Those questions included things such as "What would you title this photo?", "What are three things you like about this photo?", "What are three things I wouldn't know about you from this photo?", "What would it say if it could speak?", "Does this photo contain any secrets, and if so what are they?", "What, if anything, is missing from this photo (What would make it more complete)?"19

I then spent over an hour reviewing each participant's image with them to show how their answers to my list of questions could provide me with a lot of potentially-valuable insights that emerged while each thought they were simply talking about the photo (and accompanying "decoration") in their hands.

Pausing at the image above, I asked the same kinds of verbal "de-briefing" questions -- and then, since I am also an Art Therapist -- I volunteered some additional insights about their "photo-cardboard creations", that I had noticed (due to my extra Art Therapy knowledge), many deeper perceptions about the artwork created on this image that suggested tome some additional possible topics I would definitely want to probe further, had this been a real therapy session:

Often a drawing of a tree can be a strong symbol of self -- and this tree has a very different "top" and "bottom". The base of the trunk is very thick (solid, "grounded", although no roots are showing). But the top has only a small bit of greenery, fully enclosing the photograph, but only "one layer thick". This suggests to me a bit of "disconnection" between the two parts of the tree (the self) -which then became further emphasized when I examined the visual image of the person in the photo, who has her left arm folded across her waistline, her hand anchoring it to her belt. She is smiling warmly, but there is no "bottom half" to her body -- yet her comment in response to the question about whether there was something missing, was "Nothing is missing; the picture is complete". Further, without yet even reading the words the participant had answered with, my eyes were drawn to the two flowers (?) at the bottom right which seemed to have no connection to the ground.

All of these observations were creating a very strong resonance inside me with information I had learned about a kind of unconscious symbolism common in the art expressions of survivors of sexual abuse, I then even wondered if those flowers were "breast-like". And in the strongest example of this "extra knowledge" about such iconic symbolism for such people, I realized that her arm had neatly divided her "top half" (where she thinks and feels) from her "bottom half" where sexual abuse would have happened.

This "separation of head from rest-of-body" is something that will usually catch the attention of Art Therapists while often going unnoticed by those without such education and it is often the key for opening the door to inquiry about past sexual abuse. And since some of her written answers further supported my

${ }^{19}$ For a complete list of these questions, see pages $184-185$ of Weiser, 1993/1999. 
"hunch", I was certain this would be a topic I would explore further, if this had been a client instead of a workshop participant.

However, since this entire story appears in full elsewhere ${ }^{20}$ I will not repeat it here, and instead explain that I did later find out from this person that my "hunches" were true (and that same kind of head/body separation appeared also in other photos she had brought with her from home, although she had not noticed it, until my comments brought it into her conscious mind).

Second Self-Portrait where Art Therapy knowledge provided additional insights: In this second example below, I have shown three more appearances of this same kind of art-related pattern, in three photos taken by a participant in a different Workshop.

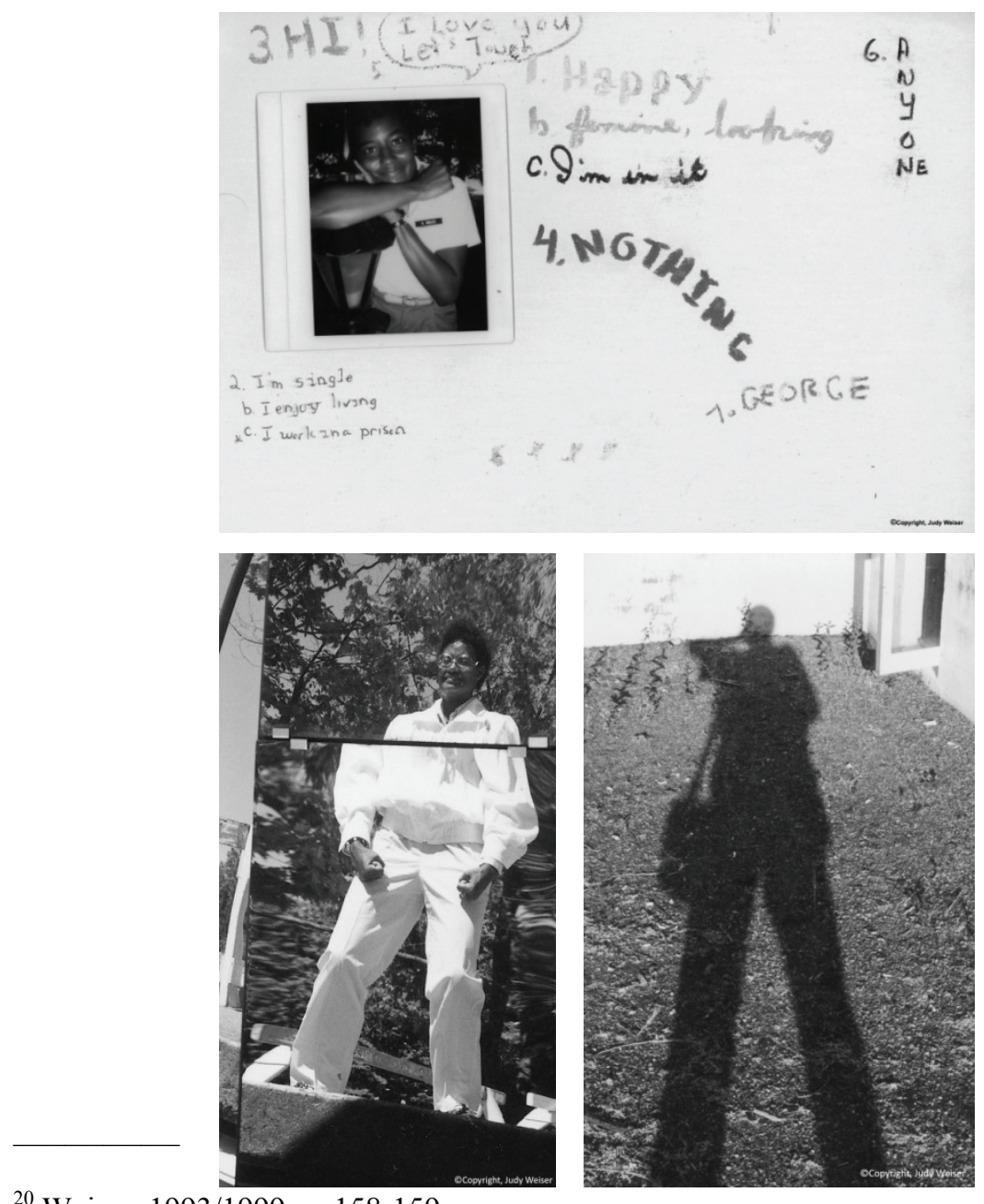

${ }^{20}$ Weiser, 1993/1999, p. $158-159$ 
The instruction for the first photo (at the top of the three above) was the same assignment as in the previous example above. She is seen in this photo as smiling, but with her right forearm across her neck and her left arm completing the "X" across her body. Her neck is not visible at all, with the result that it could seem that her head is not joined to her body...

The second and third photos were taken for a different assignment ("During the lunch-break, take ten new photos of yourself that can help you tell an important story about your life"). She chose to take the ten photos to illustrate how she felt her life changed when she joined the U.S. Army and was stationed in Alaska in a remote area, where she found few friendly people and felt quite alone.

She described these ten new photos as her posing in what she described as "entrapped" places -- and one of the others not included here showed the open fist of her arm protruding from a barred window while another one showed her facing a closed door. She explained that she had intended to convey her feelings of being ignored and/or excluded.

Her explanation for the one on the left (in the multi-paneled mirror reflection) was that it showed her "fractured" self -- and the one on the right (her "shadow" picture) was taken that way because she wanted her shadow to be on the ground in an area surrounded by walls.

Rather than putting too much emphasis on my own question about her head in the shadow seeming to be going up the wall while her shadow remained on the ground (i.e., the "head-separated-from-body" detail I had perceived in the other two photos (although not sure if she saw what I saw) -- I simply asked, as a way of getting there a bit more slowly: "Is there anything about the positioning of the shadow that you might want to arrange differently now that you see it?" She replied there was not. Then I asked "Is there anything significant for you about where the feet are? "No" again. Then I asked the question I really wanted to ask originally: "Is there anything significant for you about where your head is?"

She gave me a surprised look and said, "How did you know that I moved around until my head was going a different direction from my body?" I replied that I had not known this -- but only that I had simply noticed the difference in the shadow's appearance in the photo -- and then I asked her if this was a difference that mattered to her. She replied that she had felt vulnerable in that photographic moment -- that with only her shadow to validate her bodily existence, she had felt a bit of a "frightened" feeling and it did not resolve until she "removed her head onto the wall to separate it from her body where she could keep it safe" (her exact words) ${ }^{21}$. Then she seemed to discover for the first time (for her) that the same pattern appeared in the first two photos...

${ }^{21}$ All illustrative examples given in this Article are real -- and the people whose stories I share here (with changed names) have given their signed approval for me to use these (as well as for the exact 
Again, there is not room in this article for the full story of the process that happened in our continuation of this discussion, but I thought it was important to show how this particular kind of unconscious symbolic expression can appear much more frequently than one might expect, and that -- had I been in my first decade of using PhotoTherapy techniques (before I learned about Art Therapy) -I would have never noticed important things like these. And I am certain that numerous therapists today would not notice them either -- because they do not have any additional education or training in Art Therapy theory and interventions. And I believe that this clearly demonstrates and justifies the establishment of the sub-category of PhotoTherapy techniques named "Photo-Art-Therapy".

I hope that these examples have demonstrated how extra knowledge of Art Therapy theory and practices can be very helpful -- but are not required -- for PhotoTherapy techniques to be used effectively and beneficially in therapy sessions. The next Section will provide a "family snapshot" of the wide range of photo-based practitioners and projects currently active in Spain.

\section{Practitioners in spain}

Often when I teach or lecture in other countries, I find that there are many people there who are involved in PhotoTherapy or Therapeutic Photography practices or projects -- who I have become aware of myself through my own active networking -- but they are surprisingly unaware of each other's existence. This is one reason that I started my Facebook Group ${ }^{22}$ for sharing information about such topics.

And for this reason, I thought it important to share in this Article the names and practices of the people I know who are living in Spain, who are using these techniques and/or involved in related Social Action Photography Projects. Some of the people below are Art Therapists and some not -- but all are actively involved in the "world" of PhotoTherapy and Therapeutic Photography practices in Spain -- and for this reason I now provide a list below of "Who is Doing What, Where" in Spain, with contact information (when permitted) and a quick summary of their activities, so that readers can connect with them or view their websites, to learn more. And I do hope readers will alert me to others that I need to add to this list $^{23}$ :

\section{PhotoTherapy:}

1) Jose Bravo (Valencia) is a photographer and licensed Psychologist, specializing in Gestalt Therapy and trained as a couples therapist. As a photographer,

wording I used). All such Permission Forms are on file at the PhotoTherapy Centre and can be requested for verification if desired.

${ }^{22}$ Facebook Group for "PhotoTherapy, Therapeutic Photography, Photo Art Therapy, and VideoTherapy", at: https://www.facebook.com/groups/PhotoTherapy.and.Therapeutic.Photography

${ }^{23}$ Please send me your suggestions for recommended additions to this list, including about yourself, to: jweiser@phototherapy-centre.com 
his Projects include "First Impression": about how people "build" their image when first meeting another person and "Rencontres (with Nelly Van Oost)": which explores the intimate, everyday and family spaces of the people photographed -- while "Acompañar" is more about the approach from which he works as a photographer.

As a Gestalt Psychotherapist, he integrates the use of both past and present photographs in his psychotherapeutic practice. In his project "Self-Knowledge From Photography", he combines both disciplines in a "photo-therapeutic" context: first as a photographer accompanying the person in their day-to-day intimate spaces -- and second, in a therapeutic space, working from the Gestalt approach, accompanying the person with all the photographs taken on those emotionally moving experiences;

2) Cesar Cerón (Murcia) is a Psychiatrist and Gestalt Psychotherapist who is using photography with patients, especially the family album, the selfportrait and the projective techniques. He also conducts workshops with psychiatric patients in day centers, drawing on the techniques mentioned above (also with photographs taken by the patient in their usual environment), in which users find a space where they can share about their biographical and other emotional issues. He explains: "Patients often have difficulty developing their own autobiographical memories, and photographs allow them to catalyze these experiences -- the photos provide insights that stimulate their own creative abilities, and give them keys to deepen certain emotional aspects that help them in their own therapeutic process";

3) Begoña Martínez Pelegrín (Alicante) is a Psychologist, Neuropsychologist and Gestalt Psychotherapist (member of Spanish Association of Gestalt Therapy -- AETG) with a private practice in Neuropsychology, Psychotherapy and Phototherapy. She works in public practice in Vinalopó and Torrevieja Salud Hospitals where she serves as Neuropsychologist. Also she is Associate Professor in UCH-CEU University teaching Mental Health to future nurses. In her psychotherapy practice, she has combined psychological techniques with phototherapy by the use of photos made by the patients, and family albums, portraits and self-portraits. In Neuropsychological rehabilitation, she has used photos to recover memories, work with personal identity, the acceptance of a new condition, the autobiographical history, the actual memory and the new roles and the emotions. For that purpose she has used family photos, photos created in and outside of therapy sessions, photos that relatives make during the rehabilitation of patients and families, hobbies, etc., and portraits and self-portraits -- sometimes in combination with other kinds of verbal and visual expressions. She is interested in the use of PhotoTherapy techniques in Psychotherapy with caregivers of patients with brain condition or moderate mental illness. She has also used photographs in work with families and individuals with a variety of issues, and has facilitated workshops for nurses, psychologists and Gestalt students. She has conducted various Projects of social and participatory photography and photo therapy with families, caregivers, volunteers, and patients with a neurological 
condition -- for example, "A la calle en azul" or "Rostros". And she will begin University research about PhotoTherapy and Therapeutic Photography in different health issues and applications;

4) Carlos Canal, Hematologist and Therapeutic Photographer, has been portraying his medical patients photographically since 1999, when he began to document the therapeutic effects of photography in the context of disease, to "help patients to recover their identity, express emotions, improve their quality of life"24. His book "Recuperar la luz", is about one of his patients with leukemia who portrays and describes the process of her illness.

\section{Therapeutic Photography with individuals or for personal insight:}

1) Jose Manuel Fdez Deconde (Madrid) has been a professional Coach since 2009 and is also a documentary photographer and teacher of photography. Focusing on finding ways to combine coaching and personal growth with photography, he founded "PhoCo: Photography and Coaching", his company where he promotes the use of image and arts as a tool of personal development and social change using photography, artistic social improvement and transformation -- and where he helps people develop themselves through the use of photographic imagery, thus deepening personal and artistic self-improvement through coaching, mindfulness, art therapy, gestalt, neurolinguistic programming, creativity, Zen meditation, and others. He is also working with youth "at risk" through photography, in a social project involving coaching, participative photography and aspects of PhotoTherapy helping give them "voice" in several aspects of the person (emotional, mental, social) and giving them a way of expression in several aspects of their life: family, work, friends, love, and others).

2) Cristina Nunez (Barcelona) is a professional artist who uses the selfportrait in photography and video, and is a "self-portrait facilitator" who teaches her method The Self-Portrait Experience ${ }^{\circledR}$ in prisons, universities, museums, galleries, schools and companies around the world since 2005. She has taught at the University of Bologna, the University of Roehampton, Tampere University Hospital, the University of Turku, Turku Academy of Arts, the Domus Academy of Fashion and Design in Milan -- as well as in Milan's prisons San Vittore and Bollate, Barcelona's prisons Brians 1, Wad Ras and Lledoners, Oslo's prison Bredtveit -- and also for the Korean Phototherapy Association, Housing Works (NYC) and the Institute for the Arts in Psychotherapy (NYC), among others, as a way to stimulate the creative process and self-knowledge, and to raise selfesteem. She often works with teenagers, people with addiction issues and also with companies, in partnership with professional corporate trainers, using the self-portrait method for empowerment, self-assessment and team building. In 2014 she has participated in the European project "I AM, Memoirs of Addiction

24 From: http://www.diariosur.es/v/20100925/sociedad/carlos-canal-hamatologo-fotografo20100925.html 
Recovery" and "ClosetoMe", a self-portrait project with 250 adolescents in collaboration with the Museum of Contemporary Photography in Milan. Her work as an artist has obtained numerous awards and has been published in the international press and several monographic books and shown in exhibitions around the world, in prestigious venues such as the Mois de la Photo in Montreal 2011, the Rencontres de la Photographie in Arles (1998/2013), the Casino of Luxemburg and Palazzo Reale in Milan. More about her artwork can be found here, and more about her work with companies here -- while more about "The Self-Portrait Experience" itself can also be found on her very comprehensive website;

3) Chiara Digrandi (Madrid) is a Psychologist, Art Therapist and Facilitator of The Self-Portrait Experience ${ }^{\circledR}$. She studied music, photography and theatredance. In 2009 she carried out a project using art with a group of teenagers in Neuro rehabilitation Pediatric Hospital in Rome. In the same year she did a training in the Department of Child Psychiatry in Turku University Hospital (Finland). In 2011 in Arequipa, Peru, she carried out different photo-based projects in a women's prison, in a juvenile prison, in a various children's shelters, and in a difficult suburban district, using The Self-Portrait Experience ${ }^{\circledR}$ method, photos, art, and life-story. She used photo-based therapy in a group therapy with women with different problems (people with AIDS, victims of violence, and those living in very difficult social conditions) in collaboration with the Red Cross Organization in Madrid. In 2013-2014, during her Art Therapy Master studies in Madrid she did different training using art, photography and video in therapy in several different settings: in a psychiatric day hospital with a group of adolescents, in collaboration with Intermediae Matadero (a laboratory for the production of projects and social innovation, specialized in visual culture driven by participation), an Art Therapy project with a senior citizen group, and the "Backups" project with a group of adolescents at risk of social exclusion at the "Asociación Semilla". She is also involved in a social and democratic film project "Matáme si Puedes" ("Kill me if you can") in collaboration with Cine sin Autor (Cinema without Authors).

4) Lucia Compostu (Italian but living in Spain for 20 years) works as a coach in rehabilitation centers for social work and is certified as a trainer by the International Points of You to teach "The Coaching Game" that uses photos to help people explore themselves and various issues.

Therapeutic Photography in the form of Social Action Photography Projects:

1) NWN Photography ("NOS Why not?") is a non-profit organization created by Felipe Alonso, a Barcelona photojournalist with over 25 years in the profession, in order to give all people with intellectual disabilities, the possibility of a new inclusion through photography, empowering and making them protagonists of their lives. It is the first Photographic Agency for photographers with intellectual disabilities (there are now 45 photographers involved, including two who are blind!). 
These photography projects integrate the world of intellectual disability, and aims at improving their quality of life by opening a double door: work integration and the opportunity to enjoy a new hobby. This has been so successful that recently some of these photographers have been hired to provide photodocumentation of public events.

2) Intras Foundation (Spain) is one of the European Commission funded "ETRA (Education Through Rehabilitative Art/Photo) Projects" that happened (and continues to happen) in seven countries to assist people with mental illness, mainly depression, bipolar disorder and psychosis with self-expression and selfdiscovery through an organized series of workshops based on enhancing creativity using photography. "ETRA projects encourage new ways to use Art -- and specifically the language of Photography -- to meet the needs of disadvantaged learners developing empowerment processes and new interpersonal behaviours." 25

The workshops have resulted in a wide array of images using a variety of photographic and editorial techniques. The participants have gained confidence in their skills and have ignited their individual creative perspectives. ETRA Project has generated richer interaction and meaningful learning in the group of participants, both of which will continue to be applied by participants in different contexts of their live, not just in the class.

By acquiring new technical skills and numerous social skills the photography project has been an invaluable experience for the participants involved. During the workshops photography has ensured that all participants work as a team, cooperate among themselves, assist and appreciate the photos of other colleagues. Each session began with a short introduction to the specific project and a summary of any new skills or technical information required. Through group discussion and a mutual sharing of opinions and ideas the methodology was created and realized. Time, space and freedom of expression were afforded to the participants to allow for creativity and inspiration to develop organically ${ }^{26}$.

\section{Photo-Art-Therapy in combination with the above:}

1) David Viñuales (Huesca), Doctor in Arts Education (Barcelona University), is a professional photographer, art therapist and teacher of photography. $\mathrm{He}$ trained and has extensive experience in the following disciplines: art, photography, art therapy, psychology and pedagogy. He has done mental health projects such as using photos for well-being and therapy, young people with Asperger and Autism conditions, and also for creating "life books" for older people with Alzheimers. As a professional teacher, he conducts courses, workshops, and participates in international conferences on photography and phototherapy in Spain, Russia, Finland and France. As a photographer and artist, he has published sev-

\footnotetext{
${ }^{25}$ Quoted from "SottoSopra" at: http://www.blurb.ca/b/4342504-sottosopra

${ }^{26}$ This summary is from "ETRA Newsletter \#3": http://www.etraproject.eu/pagine/newsletter-000
} 
eral photo books, photographs for Spanish and French magazines, as well as companies from Spain and Italy and has won numerous awards as a photographer, including film festival prize for his animated video. For his professional photographic work, click here -- and for the blog he writes about photography (including portions about "photography and social transformation"), click here.

\section{Other:}

1) Miguel Ángel Huerta Floriano, Facultad de Comunicación de la Universidad Pontifica de Salamanca, is Editor of the Journal "El Cine como Terapia" -which is worth mentioning here as a "foreshadowing" of my next Article in this two-part series, which will be about VideoTherapy and Therapeutic Film-Making both during therapy or as therapeutic activity -- along with Art Therapy's intersection with both.

\section{Conclusion}

In summary, I hope that this Article has clarified for readers the similarities and differences between the techniques of "PhotoTherapy" and "Therapeutic Photography", and discussed similar differences and similarities regarding the techniques of "Art Therapy" and "Therapeutic Art" -- as well as explained how newer practices such as "Photo-Art-Therapy" and "Therapeutic Photo-Art Activities" have naturally evolved from the intersection of these paths.

I also hope that the framework provided for positioning each practice explained above, within the context of all the others will prove useful, and that the "real life" clinical illustrations also helped to clarify with visual "proof" how additional knowledge of Art Therapy can help a therapist to see more in clients' photos than could have been noticed without it -- while at the same time demonstrating the strong power of PhotoTherapy techniques when used on their own, where no art-expressive media are involved.

The goal of this Article was for readers to now be able to compare and contrast the various techniques of PhotoTherapy and Art Therapy (and related others), and better understand their similarities and differences -- as well as learn how therapists with special additional Art Therapy education can use Photo-ArtTherapy and Therapeutic Photo-Art techniques to additionally benefit their practice in a way not possible for other mental health professional and therapists without such training.

My objective was for readers to learn how the entire Continuum of photobased helping techniques can be used during therapy and/or therapeutic activities to help clients gain personal insight and awareness, improve communication with others, increase well-being, create positive individual, family, community, and/or social changes, and reduce the effects of social exclusion and marginalization -using the photos they take, pose for, collect and keep, to take back their power to share their own story, their own way (some with the help of a trained therapist, and some without it).

In learning more about the purpose of this "Art Therapy Revista" Publication, I received the following explanation when I asked about its purposes: "This 
Journal addresses various aspects of Art Therapy: clinical, educational, and social"-- and so I hope that readers will now understand that I would position PhotoTherapy and Art Therapy (therapy practices) under "Clinical" in the above description, while positioning Therapeutic Photography, Social Action Photography Projects, and Therapeutic Art Activities (photographic artistic practices) within the "Social" category ${ }^{27}$.

Additionally, I think it would be very helpful for readers to consider some implications about the effects on people's daily lives as a result of technology racing forward with exponentially-increasing speed:

The only thing that can be certain about photographic realities in the future, is the certainty that these will change; there exists no option for stopping time and progress. Therefore, it has now become essential that therapists always keep themselves updated about what is already happening technologically in the lives of their clients (especially the younger ones) or they will be left behind, unable to therapeutically communicate with them (especially visually). Therapists must become "fluent" with new technology (and its language) in order to not limit their possibilities of helping people.

Paradigm shifts are happening every day, and will forever continue to happen. Changes about the role of photos in people's daily lives, their reasons for taking, keeping, altering -- and even deleting -- them, mean that the ways that therapists will use such images in their sessions with clients, must also shift to fit the changing lives of their clients.

Therapists cannot be working with photos under assumptions that were valid in the early days of this field, with clients who now live in a different century and have a vastly changed language of photographic imagery.

New technological devices are not as important as considering the way that "ordinary people" have made such things an increasingly-commonplace (and necessary) part of their daily life -- with the result that major sociocultural shifts have emerged so smoothly and calmly, that they are not even noticed until people stop to reflect on "what is different now".

All of this has major import regarding the use of the various techniques of PhotoTherapy -- not so much in the benefits of all the extra technological devices themselves, but moreso in the fact that if therapists do not keep up with all these new advancements (and become fluent in using these themselves), they will have less awareness of the "normal" daily life of their clients -- and thus not only be less able to help them achieve wellbeing, but also very simply be quickly left behind.

\footnotetext{
${ }^{27}$ For a more thorough and longer explanation about this framework, please see the website "PhotoTherapy, Therapeutic Photography, and Related Techniques" and/or various publications authored by me in the Reference List for this Article.
} 
And if therapists do not recognize that changes are happening, they will also not realize that their assumptions about their treatment methods have likely also become outdated. All therapists should consider it their responsibility to continually re-visit their basic operating assumptions about the purpose and methods of therapy itself...

Therefore, while it is certain that the therapeutic goal of exploring the deeper meaning of the photograph below its "surface" visual details" will always be at the heart of PhotoTherapy process, it is also certain that the way that people create their personal-visual stories (their daily-life photographs) will continue to change with each new technological improvement.

The nature of these images will change, but not the reason that they want to create and keep them (the reason and purpose that photos continue to exist). The future therapeutic uses of photos will still be more about the image itself, than the technology that created them. And that is the reason that PhotoTherapy techniques are so successful -- and it is also the reason that people still continue to take and keep photos.

In closing, I cannot emphasize too strongly that technological and societal/cultural changes will inexorably continue to change people's lives so much that, if practitioners do not continually revise and update their techniques to remain current with all the new possibilities relating to the use of photos, they will simply not be able to continue helping people effectively, no matter what they name their techniques.

And therefore it seems obvious to me that all Art Therapists (and Art Therapy Students) need to be taught about PhotoTherapy and Therapeutic Photography, whether or not they eventually choose to use these techniques themselves. It is clear that not knowing enough about PhotoTherapy techniques to make informed choices during Art Therapy practice is no longer acceptable in Art Therapy education or training -- and will lead to both an incomplete education and many knowledge gaps in comparison with other therapy professionals who were taught about these techniques. Training Programs which ignore PhotoTherapy and Therapeutic Photography -- and especially Photo-Art-Therapy -- will result in only partial Art Therapy competency in their graduates, and in this new age of digital imagery and digitally-fluent clients -- such Programs will have a very difficult time surviving...

\section{References}

CORBIT. I. \& FRYREAR, J. (1992). Photo art therapy: A Jungian perspective. Springfield, IL: Charles C. Thomas.

KRAUSS, D. \& FRYREAR, J. (Eds.). (1983). Phototherapy in mental health. Springfield, IL: Charles C. Thomas.

WEISER, J. (1999, 2nd edition). PhotoTherapy Techniques: Exploring the Secrets of Personal Snapshots and Family Albums (1st edition, 1993). Vancou- 
ver, PhotoTherapy Centre Press. (To download the "Preface" or the "Foreword to the Second Edition" of this book, click on those words; to download the first Chapter (pp. 1-12), click here).

WEISER, J. (2005a). A Picture is worth a thousand words: Using PhotoTherapy Techniques in Arts (and other) Therapies practice. In: Kossolapow, L., Scoble, S., and Waller, D. (Eds.), Arts Therapies Communication (Vol. III), Different Approaches to a Unique Discipline: Opening Regional Portals, Münster: LitVerlag Publishers, 481-486.

WEISER, J. (2005b). More than meets the eye: Using PhotoTherapy techniques in Art Therapy practice. The Palette (Newsletter of the Ohio Art Therapy Association (BATA), Fall, 18-19.

WEISER, J. (2004a). PhotoTherapy techniques in counseling and therapy: Using ordinary snapshots and photo-interactions to help clients heal their lives. The Canadian Art Therapy Association Journal, Fall, 17:2, 23-53. (To download, click here).

WEISER, J. (2004b). The continuum of arts-based healing practices: Arts-inTherapy/Arts-as-Therapy. Creative Arts in Counselling Chapter Newsletter (Canadian Counselling Association), Fall, 1:2, 3. (To download, click here).

WEISER, J. (2010). Using Photographs in Art Therapy Practices Around the World: PhotoTherapy, Photo-Art-Therapy, and Therapeutic Photography. Fusion (a publication of Art Therapy Alliance, International Art Therapy Organization, and Art Therapy Without Borders), 2:3, 18-19. (To download, click here).

WEISER, J. (1975). PhotoTherapy: Photography as a verb. The B.C. Photographer, 2, 33-36. (To download, click here). 